\title{
Why Inventors Should Embrace Unequal Partnerships
}

\section{Dean Kamen (Deka Research)}

KEYWORDS: Management of Companies \& Enterprises, Entrepreneurship, Innovation, Finance, Learn From Leaders.

EDITOR'S NOTE: This article by celebrated inventor Dean Kamen kicks off a new feature for EIX, "The Entrepreneur Essay." Entrepreneurs who are famous in their own right, or who founded or headed famous companies, will share their wisdom on a factor that has been crucial to their success.

Kamen is one of the world's most famous product innovators, with patents on more than 440 inventions that have vastly benefited mankind - for example, wearable infusion pumps for delivering medication; the all-terrain iBot wheelchair; the Luke prosthetic arm that restores nearly full functioning; a water purification system with great promise for impoverished areas of the world; and his best-known invention, the Segway human transporter.

He is also the founder of the FIRST robotics competition, whose goal is to get more children and teens excited about technology and science. The recipient of numerous awards, including the National Medal of Technology from President Bill Clinton in 2000, Kamen has been called "the closest thing to a modern-day Thomas Edison." He is the founder and CEO of DEKA Research and Development, whose nearly 500 employees work at the company's headquarters in a revitalized Manchester, N.H., mill district.

My very first invention was a failure - not because it didn't work, but because I couldn't get support from the only partner who could help it take off: my mother. I was five years old. My brother (and former bed-making assistant) Bart had just moved to his own room, and I was tired of making my bed all by myself. So, inspired by my mother's pulley-operated clothesline, I used the pulley to invent a device that let me make the bed with one tug on a rope. My mother was not amused, and my invention never hit the big market.

That was an early and highly formative lesson for me on how powerful partners can make or break an innovation. Many inventors never learn this lesson, and they end up struggling with the idea of sharing the limelight and profits with stronger and firmly established partners with powerful brand, manufacturing and distribution assets. But from my experience, inventors who want their products to gain market traction may need to do two things that many of them instinctively hate to do: cede a lot of control to outside business partners with crucial capabilities (e.g., in manufacturing, distribution and sales), and let those partners reap an appropriate share of the profits.

If you're an inventor like me, you may find this thought revolting. But over the years, l've learned that sometimes only a powerful business partner can get your product into the hands of the people who can benefit most from it. This has been very important for my own company, DEKA, because it allows us to focus on inventing products that help people who are disadvantaged physically and economically. Some of these products can be costly to produce in lower volumes, but our partners can help us get them to more people more efficiently. For example, Toyota Motor Corp. is helping us with our new generation of the іBOTTM Mobility System, which helps people with disabilities travel over rough terrain, go up stairs, and interact with standing people at eye level. In still another effort, we are currently working with the Department of Defense and 87 other partners - academic institutions and companies - to advance the field of regenerative medicine.

\section{The Challenge of Giving up Control}

Understandably, many new inventors yearn to keep every phase of their innovation under their own control. If you've invested much in a breakthrough invention, technology or product, it's natural to want to reap all of the rewards from your ingenuity and hard work. You may feel that, "I've got a great new idea, and that's 
where the value lies. I want to own and control all of that value, and everybody else is incidental."

That type of thinking is a huge mistake.

Great ideas alone are not marketable products. To take them out of the realm of a science fair project or a novelty, scale up production, make them affordable, and figure out how to get them to market requires resources that many inventors don't have. Those resources include time and money, an understanding of manufacturing and logistics, quality control and distribution, and sales and marketing acumen. A powerful partner or set of partners can offer this and deliver your innovation to a global market. But to make their investment worthwhile, it will often require that they get a significant share of the profits.

That might seem like a bum deal for the inventor. But remember that a small slice of a global market is still a handsome payoff, and it's much better than a whole lot of nothing.

\section{How I Learned This Lesson}

After my initial lesson from my mother, I saw it play out again in my first commercial ventures. In 1976, my brother Bart, by then a doctor, asked me to develop an infusion pump that could deliver precise amounts of medication to his pediatric patients. That's how the AutoSyringe, my first medical invention, came about. While I earned enough money from its earliest versions to build a small manufacturing facility, I discovered that we needed many more versions of the AutoSyringe to help more kinds of patients. The clinical testing and subsequent marketing efforts required for that was beyond what I could do effectively in a small company, so I sold AutoSyringe to Baxter International a few years later.

Product inventors must think hard about what it will take to deliver their innovation into the most hands and whether they have those skills. The post-invention process requires discipline, focus, an attention to detail, and a lot of patience. I don't have those qualities, nor do many inventors. We are impatient and creative, and we are most comfortable working without a map. That is why we don't work for big companies in the first place. That is why my company, DEKA, allows our nearly 500 inventors to take risks, explore the unknown, make mistakes and learn from them. We often know roughly where we need to go, but we understand that it is often necessary to explore and endure some missteps before we land on something solid.

But the very unmapped nature of our work -- exploring, inventing, learning from mistakes and perfecting leaves few resources for the other critical tasks needed to fulfill the vision for the product. Tasks such as scaling up the manufacturing to high volume and doing worldclass marketing and distribution are better left to others. That's where partners come in.

\section{Four Lessons for Inventors Everywhere}

I've found four steps to be essential in finding the right business partners:

\section{Focus first on what you do best.}

Clarify what you hope your invention will accomplish, and focus on what makes it unique. Then build a prototype, refine it and perfect it, and don't worry about how you will get it to market. Do all the work that lowers the risk of your invention - the barriers that (if not overcome) may prevent you from achieving your ultimate vision for it. Before you look for a partner, make sure your invention does everything you claim it will do. If you have problems getting partners on board, it may be because you haven't perfected your innovation and demonstrated that it works and provides value.

\section{Find a business partner that shares your vision, has integrity, and believes in you.}

Toyota shares our vision for the iBOT: helping people who can't walk to regain not only mobility - any wheelchair can give them some of that -- but also their freedom, independence and humanity. Our earliest versions of the $\mathrm{BBOT}$ would have been far too expensive for most people. However, a venerable company like Toyota with more than eight decades in the transportation business can help us manufacture it far less expensively than we otherwise could, and deliver it to farthest reaches of the world and into the lives of many more people.

\section{Find a partner with the manufacturing, marketing and distribution firepower you need.}

Slingshot ${ }^{\mathrm{TM}}$, our portable water purification system, holds great promise for underdeveloped countries that lack clean water. It's difficult to get it to the remote villages that need it most. However, the Coca-Cola Co. 
has the world's greatest distribution network for beverages and has helped us conduct trials of the Slingshot in locations that would be not have been accessible to us. Your partner may not be as big or famous, but should have the capabilities to bring your innovation to market.

\section{Protect yourself and your partner.}

A partnership agreement must spell out the vision and the expectation of both parties. It must also give both sides an out if they encounter irreconcilable differences, or if either side can't honor the intent of the agreement. Such a contract provides a rational path ahead if things fall apart, when emotions are likely to run high and cloud your vision. Occasionally I have had to terminate a relationship with a partner and a properly drafted agreement made it much easier.

Even with an ideal and very fair partner, an inventor must realize that the time, money and expertise required to bring a product to market will often far outweigh what was needed to invent it, and the division of the profits may reflect this. As a longtime inventor, that doesn't bother me one bit. That's because I don't count my partners' money -- I only count mine. Fortunately, my share has been more than enough to help finance future innovations and to keep my nearly 500 DEKA engineers productive and happily developing our next big ideas.

Most importantly, the inventions that people truly need to make their lives better now have a real shot at getting to them.

Additional search terms: business partnerships, finding a partner, commercializing my idea, scaling up, getting my product to market, blockbuster product, mass-producing my product, mass production 